\title{
CONE-950961--10
}

\section{LOW-TEMPERATURE RADIATION EMBRITTLEMENT OF COPPER ALLOYS}

\author{
S.A. Fabritsiev1 ${ }^{1}$ A.S. Pokrovsky², S.J. Zinkle ${ }^{3}$, D.J. Edwards ${ }^{4}$ \\ ${ }^{1}$ D.V.Efremov Scientific Research Institute, 189631 St.Petersburg, Russia. \\ ${ }^{2}$ Scientific Research Institute of Atomic Reactors, 433510 Dimitrovgrad, Russia. \\ ${ }^{3}$ Oak Ridge National Laboratory, P.O. Box 2008, Oak Ridge, TN 37831-6376 USA \\ ${ }^{4}$ Pacific Northwest Laboratory, P.O. Box 999, Richland, WA 99352 USA
}

\begin{abstract}
The effect of low-temperature ( $\mathrm{T}_{\mathrm{irr}}$ less than $0.3 \mathrm{~T}$ melt) irradiation on the tensile properties of copper and precipitation-hardened (PH) and dispersion-strengthened (DS) copper alloys was investigated. Samples were irradiated with fission neutrons at temperatures of 80 to $200^{\circ} \mathrm{C}$ to doses of 0.6 to $5 \mathrm{dpa}$. Irradiation at temperatures $<150^{\circ} \mathrm{C}$ resulted in significant hardening and accompanying embrittlement in all of the materials. By comparing the present results with literature data, it is concluded that severe radiation embrittlement occurs in copper alloys irradiated at temperatures $\leq 100^{\circ} \mathrm{C}$ for doses above $\sim 0.01$ to $0.1 \mathrm{dpa}$. On the other hand, irradiation at temperatures above $150^{\circ} \mathrm{C}$ causes only moderate embrittlement for doses up to $\sim 5$ dpa. It is recommended that the minimum operating temperature for copper alloys intended for structural applications in fusion energy systems should be $150^{\circ} \mathrm{C}$, unless uniform elongations $<1 \%$ can be accomodated in the design.
\end{abstract}

Key words: yield strength, uniform elongation, total elongation, radiation hardening corresponding author: S.J. Zinkle, tel. 423-576-7220, fax 423-574-0641, email zinklesj@ornl.gov

"The submitted manuscript has been authored by a contractor of the U.S. government under contract NO. DE-ACOS960R22464. Accordingly, the U.S. Govemment retains a nonexclusive, royalty-free license to publish or reproduce the published form of this contribution, or allow others to do so, for U.S. Government purposes." 


\section{Introduction}

The use of copper alloys as a structural material for the ITER first wall and divertor poses before materials scientists a large variety of challenging problems. In many respects these problems arise from a lack of knowledge about the mechanical properties of copper alloys irradiated at ITER relevant conditions $\left(50\right.$ to $350^{\circ} \mathrm{C}$, doses up to $\left.\sim 10 \mathrm{dpa}\right)$. Previous work on pure copper $[1,2]$ and copper alloys [3-9] has shown that significant radiation hardening and loss of ductility occurs in these materials following neutron irradiation at temperatures below $250^{\circ} \mathrm{C}$. These studies suggest that low-temperature irradiation to doses as low as $\sim 0.1$ dpa may cause substantial embrittlement of copper alloys. However, the data base on precipitation-hardened (PH) and dispersion strengthened (DS) copper alloys at irradiation temperatures below $250^{\circ} \mathrm{C}$ is very limited. There are only a few known studies of the tensile properties of these materials at damage leveis $>1 \mathrm{dpa}$ at irradiation temperatures $<200^{\circ} \mathrm{C}$, where radiation hardening and embrittlement effects are most pronounced [3-6,8]. The present study summarizes recent results obtained on copper and copper alloys irradiated at $80-200^{\circ} \mathrm{C}$ to doses between 0.6 and 5 dpa. These data represent a subset of a collaborative irradiation program that investigated the electrical and mechanical properties of copper and copper alloys irradiated at temperatures between 80 and $400^{\circ} \mathrm{C}$ and doses of 0.6 to $5 \mathrm{dpa}$ [3].

\section{Experimental Procedure}

Sheet tensile specimens from copper (Russian Federation (RF) $\mathrm{Cu}, 99.97 \%$ purity and A.D. Mackay $\mathrm{Cu}, 99.999 \%$ purity), DS copper alloys (GlidCop A125, GlidCop Al15, MAGT-0.2, $\mathrm{Cu}-\mathrm{Mo}$ ), and a $\mathrm{PH}$ copper alloy ( $\mathrm{Cu}-\mathrm{Cr}-\mathrm{Zr}$ ) were irradiated in the Channel 4 and Core positions of the SM-2 reactor. Most of the materials were irradiated in both annealed and cold worked conditions. Two types of sheet tensile specimens were irradiated and tested. The large tensile specimens (LTS) had an overall length of $56 \mathrm{~mm}$ and a thickness of $1 \mathrm{~mm}$, with a gage length and width of 30 and $4 \mathrm{~mm}$, respectively. The small tensile specimens (STS) had an overall length of $34 \mathrm{~mm}$ and a thickness of $0.25 \mathrm{~mm}$, with a gage length and width of 11 and $3.5 \mathrm{~mm}$, respectively. The irradiated and control samples were tensile tested in vacuum $\left(\sim 10^{-4} \mathrm{~Pa}\right)$ at a crosshead speed of $\sim 1 \mathrm{~mm} / \mathrm{min}$ in the temperature range of $20-400^{\circ} \mathrm{C}$, which corresponds to an initial strain rate of $5.6 \times 10^{-4} / \mathrm{s}$ and $1.5 \times 10^{-3} / \mathrm{s}$ for the LTS and STS specimens, respectively. For the elevated temperature tests, the tensile specimens were held at temperature for 0.5 hour prior to testing. The fracture surfaces were investigated by scanning electron microscopy (SEM).

The specimens were irradiated in the Channel 4 position to doses of 0.6 to $1.4 \mathrm{dpa}$ ( 0.8 to $2 \times 10^{25}$ $\mathrm{n} / \mathrm{m}^{2}, \mathrm{E}>0.1 \mathrm{MeV}$ ) at $\mathrm{T}_{\mathrm{irr}} \sim 100$ and $200^{\circ} \mathrm{C}$, as well as to doses of $\sim 3$ to $5 \mathrm{dpa}$ at $\mathrm{T}_{\mathrm{irr}} \sim 100$ and 
$250^{\circ} \mathrm{C}$ in the Core position. The average fast ( $\left.\mathrm{E}>0.1 \mathrm{MeV}\right)$ and thermal neutron fluxes were $3 \times 10^{18}$ and $2.5 \times 10^{18} \mathrm{n} / \mathrm{m}^{2}$-s, respectively, in the Channel 4 position, and $1.7 \times 10^{19}$ and $1.9 \times 10^{18}$ $\mathrm{n} / \mathrm{m}^{2}-\mathrm{s}$, respectively, in the Core position. In order to recuce the solid transmutation production rate to fusion-relevant levels, some of the samples in the Channel 4 region were irradiated in Cdshielded capsules, thus making it possible to considerably suppress the thermal neutron flux. The thermal neutron flux in the Cd-shielded Chamnel 4 capsules was $\sim 3.6 \times 10^{17} \mathrm{n} / \mathrm{m}^{2}$-s. Further details on the irradiation technique and capsule design are presented elsewhere $[3,10]$.

\section{Experimental results.}

Fig. 1 shows the measured yield strength and total elongation in annealed and cold-worked pure copper after irradiation in the Channel 4 and Core positions at $\sim 100^{\circ} \mathrm{C}$. Also included in Fig. 1 are low-dose data by Makin [1] on cold-worked and annealed copper for the sake of comparison. It is apparent that low-temperature irradiation hardens pure copper, with an accompanying decrease in ductility. The data suggest that the radiation hardening in annealed copper has saturated at a dose of $\sim 0.1 \mathrm{dpa}$. One interesting feature is that annealed and cold worked copper samples demonstrate nearly the same increase in yield strength following irradiation to $\sim 1 \mathrm{dpa}$, i.e. $\Delta \sigma_{y} \approx 200 \mathrm{MPa}$, though the final result for cold worked copper is $\sigma_{\mathrm{y}} \approx 420 \mathrm{MPa}$, and for annealed $\mathrm{Cu}$ it is $\sigma_{\mathrm{y}} \approx 250 \mathrm{MPa}$. The corresponding ductility for annealed copper is reduced by irradiation at $\sim 100^{\circ} \mathrm{C}$, with a typical irradiated uniform elongation of $\sim 5-10 \%$ and total elongation of $\sim 10-20 \%$, respectively. For cold worked copper the embrittlement is more dramatic and the uniform elongation decreases to $0.2-1.1 \%$ after irradiation to $\sim 1$ dpa. The data in Fig. 1 suggest that radiation hardening of cold-worked copper is maximized at a damage leveis of $\sim 1$ dpa. Irradiation of a cold-worked copper specimen to a damage level of $\sim 5$ dpa resulted in a lower strength and higher ductilty compared to $1 \mathrm{dpa}$, suggesting that radiation-enhanced dislocation recovery may be occuring at the higher dose. Additional data are needed to confirm the apparent high-dose ( $\sim 5 \mathrm{dpa})$ softening behavior in cold-worked copper. Overall, these data suggest that the yield strengths of cold-worked and annealed copper irradiated at $\sim 100^{\circ} \mathrm{C}$ are significantly different for damage levels below $\sim 1 \mathrm{dpa}$, and tend to converge toward a common value at high damage levels $(\geq 5 \mathrm{dpa}$ ). Specimens of amnealed and cold-worked copper irradiated in the Core position to a dose of 3 to $5 \mathrm{dpa}$ at $\sim 100^{\circ} \mathrm{C}$ exhibited good ductility, with uniform elongations of 9.5 to $19.5 \%$ and total elongations of 12 to $21 \%$.

It is worth noting that a different tendency toward embrittlement was observed in the RF copper LTS and STS specimens irradiated in the annealed condition, most likely due to different procedures for specimen fabrication. The RF Cu STS specimens were made from a $1 \mathrm{~mm}$ sheet (from which the LTS samples were also cut out) that was cold rolled to a thickness of $0.2 \mathrm{~mm}$ 
with several intermediate anneals at $350^{\circ} \mathrm{C}$ for $1 \mathrm{~h}$. It seems likely that the RF copper LTS specimens may not have fully recrystallized during preirradiation annealing at $350^{\circ} \mathrm{C}$ for $1 \mathrm{~h}$, due to the low amount of cold-work in the as-wrought $1 \mathrm{~mm}$ sheet. As a result of the differences in processing history, the LTS samples of annealed RF copper hardened and embrittled more than the STS specimens. The 3 data points for annealed RF copper that are located outside of the shaded data bands in Figs. la and $1 \mathrm{~b}$ correspond to the LTS specimens, and they exhibit tensile behavior that is intermediate between the annealed and cold-worked copper trend lines. It is also worth noting that the yield strength was slightly higher (and the uniform and total elongations were lower) for specimens irradiated in the unshielded Channel 4 capsule regions compared to Cd-shielded specimens (cf. Fig. 1). As discussed elsewhere [11], this implies that the higher concentrations of transmutation solutes in the unshielded capsules may enhance the residual radiation defect cluster density.

As demonstrated in Fig. 2a, the yield strength of Glidcop Al25 and MAGT-0.2 alloys irradiated at $\sim 100^{\circ} \mathrm{C}$ increased by $\sim 150 \mathrm{MPa}$ at the lowest dose investigated $(\sim 0.8 \mathrm{dpa})$. Figure 2 also includes low-dose data on GlidCop A125 obtained by Heinisch and coworkers [7,12]. The data in Fig. 2 indicate that radiation hardening in DS copper approaches a saturation level during irradiation at $36-100^{\circ} \mathrm{C}$ for damage levels above $\sim 0.1 \mathrm{dpa}$.

The behavior of the uniform elongation of the irradiated DS copper alloys was similar to that of cold worked copper. The value of the uniform elongation decreased to 0.1 to $1 \%$ in specimens irradiated at $\sim 100^{\circ} \mathrm{C}$, with corresponding total elongations in the range of 0.2 to $4 \%$. However, it should be noted that the relative degree of radiation embrittlement is considerably less in DS copper alloys; the degree of reduction in uniform elongation is about ten-fold for cold worked copper, whereas it is only a factor of 3 to 4 reduction for DS copper alloys. Fig. 2b summarizes the data base on dose-dependent uniform elongation of DS copper alloys irradiated at temperatures of $36-100^{\circ} \mathrm{C}[7,12]$. It can be seen that severe embrittlement $\left(\delta_{\mathrm{u}} \sim 0.5 \%\right)$ occurs in DS copper for doses above $0.01 \mathrm{dpa}$ at these low irradiation temperatures. The $\mathrm{Cu}-\mathrm{Cr}-\mathrm{Zr}$ radiation hardening behavior was very similar to that observed in the DS copper alloys. For example, irradiation of $\mathrm{CuCrZr}$ at $88^{\circ} \mathrm{C}$ to a dose of $1.5 \mathrm{dpa}$ increased the yieid strength to -410 $\mathrm{MPa}$, and the uniform and total elongation decreased to $\sim 0.1 \%$.

The load-elongation curves of the irradiated specimens exhibited varying behavior, depending on the specimen geometry and irradiation conditions. Yield drops were observed in the engineering stress-strain curves of the irradiated DS copper alloys, followed by low levels of work hardening. A slight yield drop was also observed in the annealed RF copper LTS specimens and coldworked copper STS specimens irradiated in Channel 4 to $\sim 1 \mathrm{dpa}$. On the other hand, yield drops 
were not observed in specimens which exhibited higher ductility values, in particular the annealed copper STS specimens irradiated in Channel 4 to $\sim 1 \mathrm{dpa}$ and both annealed and cold-worked copper irradiated in the Core position to 3-5 dpa. The post-yield work hardening rates were very low in all of the specimens irradiated at temperatures $<150^{\circ} \mathrm{C}$, which resulted in ultimate tensile strengths that were similar to the $0.2 \%$ yield strength.

The SEM investigations of the fracture character in unirradiated and irradiated samples revealed that annealed copper fractures in a transgranular manner (dimpled fracture surface) both in the initial and irradiated state after an appreciable local deformation (Fig. 3a,3b). The fracture surface of the irradited DS alloys appears more brittle, in particular necking in the irradiated samples is nearly absent (Fig. 3c). However, high magnification SEM observations on the irradiated DS copper fracture surfaces clearly indicate the prevalence of dimpled transgranular fracture (Fig. 3d).

\section{Discussion.}

The present results confirm previous observations that low temperature $\left(-100^{\circ} \mathrm{C}\right)$ irradiation causes severe embrittlement in cold-worked copper [1] and high strength PH and DS copper alloys $[4,6,7]$. It is particularly noteworthy that cold-worked copper exhibits increased radiation hardening and embrittlement compared to annealed copper (Fig. 1). The presence of a yield drop followed by a low work hardening rate in the engineering stress-strain curves indicates that the low-temperature embrittlement results from localization of the intragranular deformation in the samples (i.e., "dislocation channeling") [13-16]. The extreme localization of the deformation associated with dislocation channeling would explain the low values of uniform and total elongations observed in the irradiated specimens. TEM investigations of the irradiated samples microstructure are in progress, and should provide additional information about the embrittlement mechanism.

Of special interest is the effect of irradiation temperature on the magnitude of radiation embrittlement. When plotting the generalized curves for the dependence of total and uniform elongations in DS and PH alloys on the irradiation temperature in Figs. 4, 5 (and considering previously published data $[4,7,9]$ ), it is apparent that irradiation of the $\mathrm{PH}$ and DS copper alloys at temperatures of $80-120^{\circ} \mathrm{C}$ produces uniform elongations of only 0.1 to $1.1 \%$ and corresponding total elongations of 0.1 to 3.9\%. As demonstrated in Figs. 4, 5 and elsewhere [11], the radiation hardening decreases rapidly for irradiation temperatures $>150^{\circ} \mathrm{C}$, with a corresponding improvement in the uniform and total elongations. Previous work [17] has shown that the microstructure of copper does not vary to a significant degreee for irradiation temperatures between 50 and $\sim 150^{\circ} \mathrm{C}$, which agrees with the relative independence of the tensile 
properties on irradiation temperature in this range. Irradiation of copper at temperatures above $\sim 150^{\circ} \mathrm{C}$ produces a rapid decrease in defect cluster density with increasing temperature [17], and therefore the radiation hardening and embrittlement effects become small. Since materials with uniform elongations $<1 \%$ are classified as "brittle", the present results indicate that the operating temperature for the copper alloys in ITER should be maintained above $150^{\circ} \mathrm{C}$ uniess the engineering design can accomodate brittle materials.

When using our data and those obtained in [5-7], it is possible to determine the generalized influence of dose and irradiation temperature on the embrittlement of PH and DS copper alloys. As seen in Fig 6, both the $\mathrm{PH}$ and DS copper alloys experience a significant loss in their total elongation at $T_{\mathrm{irr}} \sim 100^{\circ} \mathrm{C}$ for doses above $-0.01 \mathrm{dpa}$, and the embrittlement appears to be neariy independent of dose in the range of $\sim 0.01$ to $10 \mathrm{dpa}$. At $\mathrm{T}_{\mathrm{irr}} \sim 150^{\circ} \mathrm{C}$ in the dose range of 0.1 to 10 dpa, the total elongation of irradiated $\mathrm{PH}$ and DS alloys was $\sim 50 \%$ of the initial value. At $\mathrm{T}_{\mathrm{irr}}>200^{\circ} \mathrm{C}$ (not shown in Fig. 6), the total elongation of the irradiated $\mathrm{CuCrZr}$ and DS alloys was more than $60 \%$ of the initial elongation up to doses of $10 \mathrm{dpa}$. The decrease in the uniform elongation following low temperature irradiation was even more pronounced than the decrease in the total elongation. Significant scatter is evident in the data plotted in Fig. 6, which implies that the radiation embrittlement has increased the sensitivity of the irradiated specimens to surface imperfections (notch acuity) and/or slight misalignments in the tensile specimen grips. The: higher surface-to-volume ratio of the STS specimen geometry compared to the LTS geometry in the present study may have accentuated this sensitivity to surface imperfections; as demonstrated in Fig. $6 \mathrm{~b}$, the total elongations of GlidCop A125 specimens irradiated at $\sim 90^{\circ} \mathrm{C}$ were significantly lower for the STS geometry compared to the LTS geometry. However, there was no noticeable elongation difference between the STS and LTS geometries for specimens irradiated at $\sim 150^{\circ} \mathrm{C}$.

\section{Conclusions}

The present tensile results demonstrate that low temperature radiation embrittlement may have a considerable impact on the use of high-strength copper alloys for ITER structural applications. Low temperature radiation embrittlement is found to be very sensitive to the irradiation temperature. For $\mathrm{PH}$ and DS copper alloys, $150^{\circ} \mathrm{C}$ appears to be a critical temperature for manifestation of embrittlement. The high-strength alloys embrittle dramatically at $\mathrm{T}_{\mathrm{irr}}<150^{\circ} \mathrm{C}$, with uniform and total elongations close to zero. The plastic flow at the deformation is unstable under these irradiation conditions. At $\mathrm{T}_{\mathrm{irr}}>150^{\circ} \mathrm{C}$ the $\mathrm{PH}$ and DS alloys have a satisfactory level of ductility, with irradiated elongations in the range of 50 to $90 \%$ of the unirradiated values. 
For irradiation temperatures below $100^{\circ} \mathrm{C}$, the radiation bardening and embrittlement becomes observable in high strength copper alloys at doses as low as $\sim 0.001 \mathrm{dpa}$. The radiation hardening and embrittlement effects reach an apparent saturation condition for doses above $-0.1 \mathrm{dpa}$ These results suggest that high-strength copper alloys proposed for use in the ITER first wall and divertor should be operated at temperatures above $150^{\circ} \mathrm{C}$ in order to maintain satisfactory levels of ductility.

\section{Acknowledgements}

The GlidCop AL25 material used in this study was provided by Dr. B.N. Singh from Risø National Laboratory. The authors thank Drs. V.R. Barabash, F.A. Garner, and A.F. Rowcliffe for their assistance during the initial stages of this research program. This research was sponsored in part by the Office of Fusion Energy, U.S. Deparment of Energy under contracts DE-AC0596OR22464 with Lockheed Martin Energy Research Corp. and DE-AC06-76RLO 1830 with Battelle Memorial Institute. 


\section{References}

[1] M.J. Makin, in Radiation Effects (Gordon \& Breach, New York, 1967) pp. 627-669.

[2] S.J. Zinkle, in $15^{\text {th }}$ Int. Symp. on Effects of Radiation on Materials, ASTM STP 1125, eds. R.E. Stoller et al. (Amer. Soc. Testing Mater., Philadelphia, 1992) pp. 813-834.

[3] S.A. Fabritsiev, A.S. Pokrovsky, S.J. Zinkle, A.F. Rowcliffe, B.N. Singh, F.A. Garner and D.J. Edwards, in Fusion Reactor Semiann. prog. report for period ending Sept. 30, 1994, DOE/ER-0313/17, pp. 221-228..

[4] S.A Fabritsiev, A.S. Pokrovsky, V.R. Barabash, and Yu.G. Prokofiev, Neutron spectrum and transmutation effect on properties of copper alloys, Fusion Eng. and Design, in press

[5] W. Vandermeulen, V. Massaut, J. Van der Velde and W. Hendrix, in Proc. 14 ${ }^{\text {th }}$ Symp. on Fusion Technology, Pergamon Press, New York, 1986, pp 1031-1035

[6] P. Fenici, D.J. Boerman, G.P. Tartaglia, J.D. Elen. J. Nucl. Mater. 212-215 (1994) 399403.

[7] H.L. Heinisch, M.L. Hamilton, W.F. Sommer and P.D. Ferguson, J. Nucl. Mater. 191-194 (1992) 1177-1182.

[8] I.V. Gorynin, S.A. Fabritsiev, V.V. Rybin, V.A. Kasakov, A.S. Pokrovskii, V.R. Barabash and Y.G. Prokofiev, J. Nucl. Mater. 191-194 (1992) 401-406.

[9] D.J. Edwards and B.N. Singh, private communication (1995)

[10] A.S. Pokrovsky, A.A. Melder, and S.A. Fabritsiev, Methodology of spectral tailoring experiment in SM-2 reactor, presented at ICFRM-7

[11] S.A. Fabritsiev, A.S. Pokrovsky, S.J. Zinkle, A.F. Rowcliffe, D.J. Edwards, F.A. Garner, V.A. Sandakov, B.N. Singh, and V.R. Barabash, The effect of neutron spectrum on the mechanical and physical properties of pure copper and copper alloys, ICFRM-7, these proceedings

[12] H.L. Heinisch and C. Martinez, J. Nucl. Mater. 141-143 (1986) 883.

[13] J.L. Brimhall and B. Mastel, Appi. Phys. Lett. 9 (1966) 127.

[14] J.V. Sharp, Phil. Mag. 16 (1967) 77.

[15] J.V. Sharp, Rad. Effects 14 (1972) 71.

[16] L.M. Howe, Rad. Effects 23 (1974) 181-195.

[17] S.J. Zinkle, A. Horsewell, B.N. Singh and W.F. Sommer, J. Nucl. Mater. 212-215 (1994) 132-138. 


\section{Figure captions}

Fig. 1. Effect of low temperature neutron irradiation on (a) yield strength and (b) total elongation of copper determined in this study and by Makin [1]. The open and filled symbols denote specimens that were annealed and cold-worked; respectively, prior to irradiation. The 3 open data points lying outside of the data bands are annealed RF Cu LTS specimens that did not recrystallize during annealing (see text).

Fig. 2. Effect of low temperature irradiation on the (a) yield strength and (b) uniform elongation of DS and PH copper alloys that were tensile tested at $100^{\circ} \mathrm{C}$ in the present study. Low-dose data by Heinisch and coworkers $[7,12]$ that were tensile tested at $20^{\circ} \mathrm{C}$ are included for the sake of comparison.

Fig. 3. Fracture surfaces of (a,b) pure annealed $\left(350^{\circ} \mathrm{C}\right) \mathrm{RF}$ copper and (c,d) MAGT 0.2 dispersion strengthened copper, following irradiation at $85^{\circ} \mathrm{C}$ to $\sim 1$ dpa and tensile testing at $100^{\circ} \mathrm{C}$. The width of the micrographs in Figs. $3 \mathrm{~b}$ and $3 \mathrm{c}$ corresponds to $-40 \mu \mathrm{m}$.

Fig. 4. Effect of irradiation temperature (dose $\sim 1 \mathrm{dpa}$ ) on the uniform elongation of $\mathrm{Cu}-\mathrm{Cr}-\mathrm{Zr}$, according to data from the present study and refs. $[4,6,8]$.

Fig. 5. Effect of irradiation temperature (dose $\sim 1 \mathrm{dpa}$ ) on the uniform elongation of GlidCop A125. and MAGT 0.2 (DS) alloys obtained from the present study and ref. [7].

Fig. 6. Dose dependence of the ratio of irradiated to unirradiated total elongation $\varepsilon_{\text {ir }} / \varepsilon_{\text {unir }}$ of (a) $\mathrm{CuCrZr}$ and (b) DS copper alloys. The open symbols refer to irradiation and test temperatures below $\sim 110^{\circ} \mathrm{C}$, and the closed symbols correspond to temperatures of $150-200^{\circ} \mathrm{C}$. The data were compiled from the present study and literature results [5-7]. 
Fabritsicu etal. Fig. la

Radiation Hardening In Pure-Copper

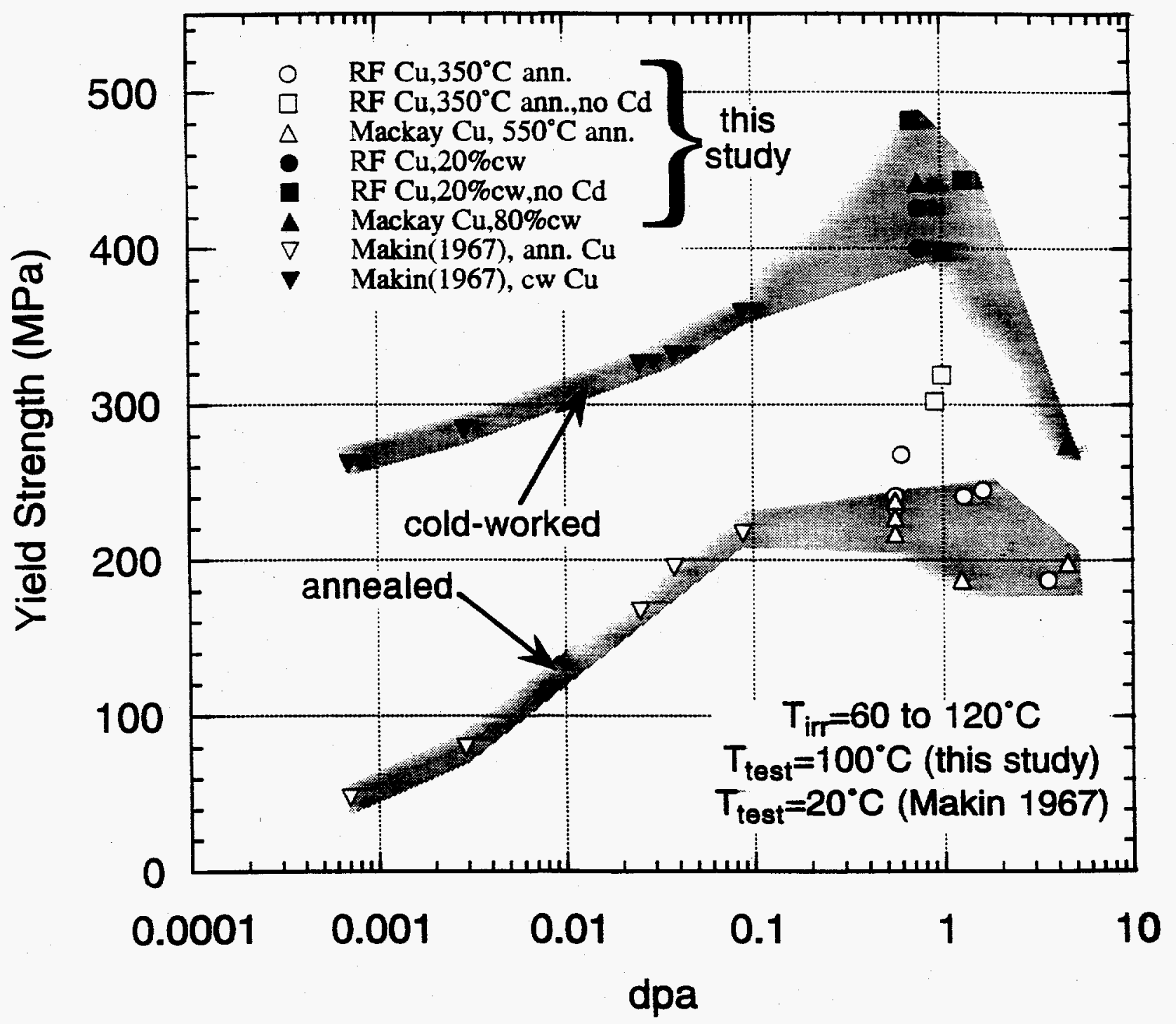


Fabritsiev etal. Fig. 16

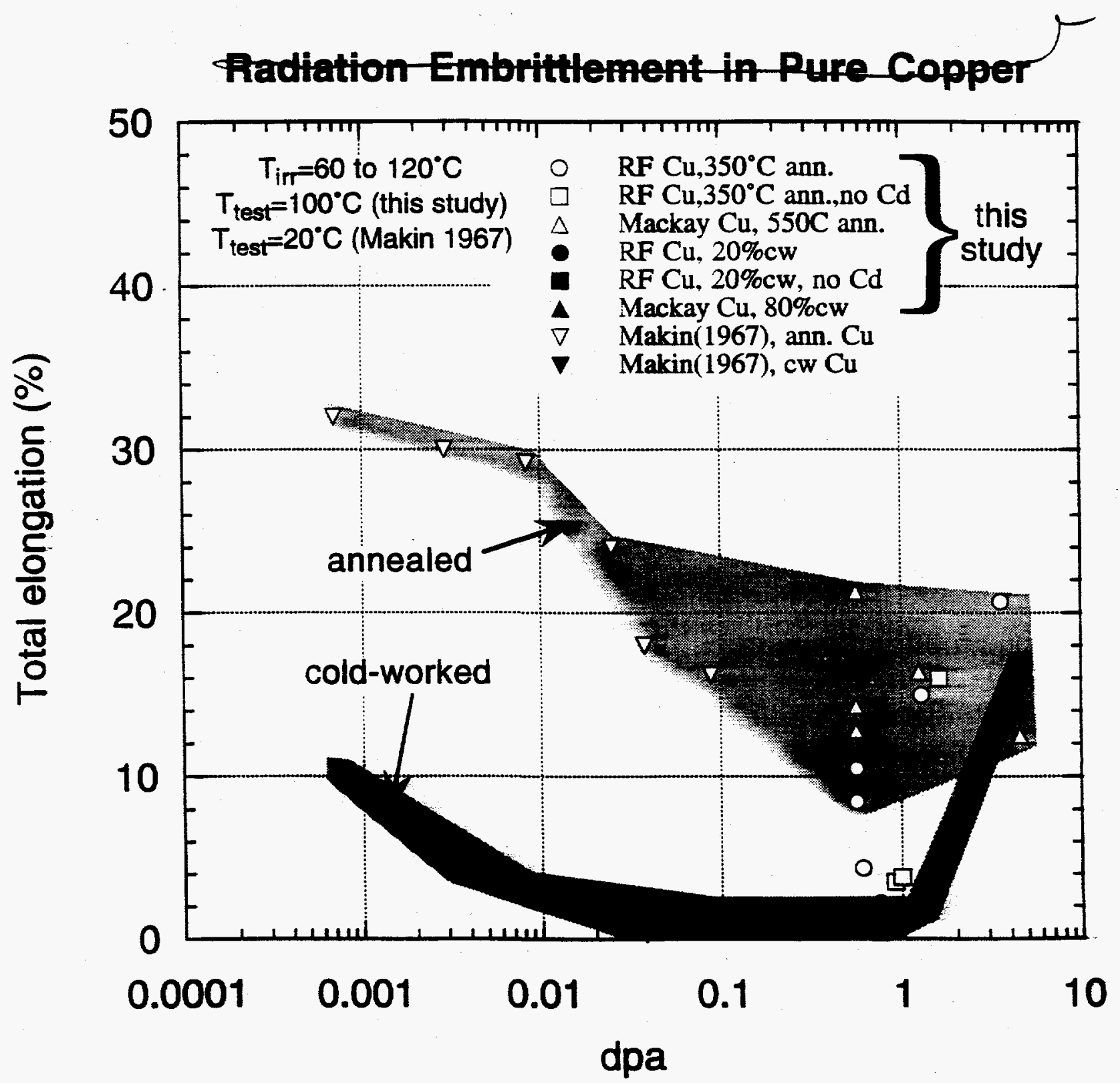




\section{Fabritsreu etal. \\ Fig. 20}

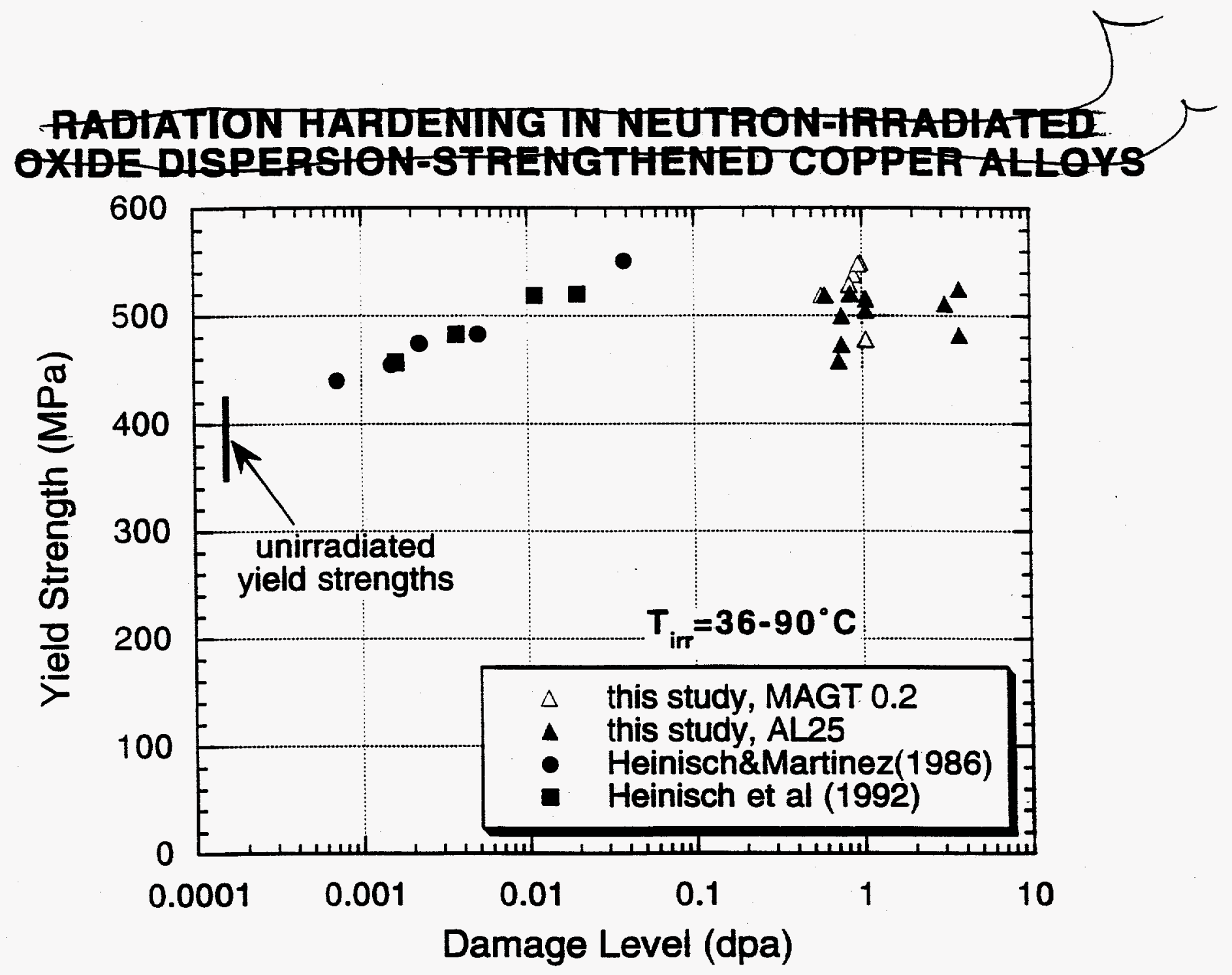




\section{Fabritsier etal. Fig 26}

\section{RADIATION EMBRITTLEMENT OF-NEUTRON IRRABIATED OXIDE DISPERSION STRENGTHENED COPPER ALLOYS}

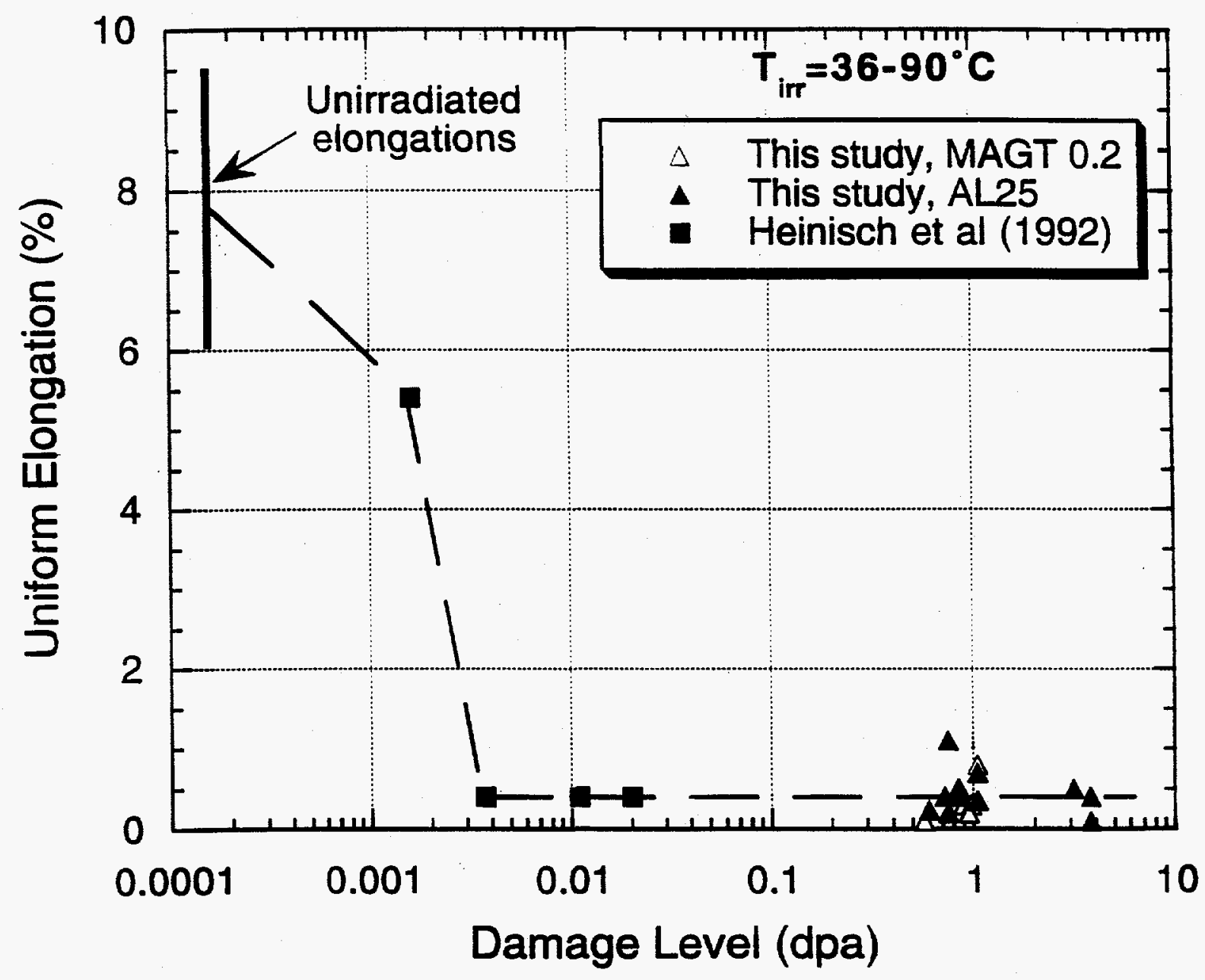



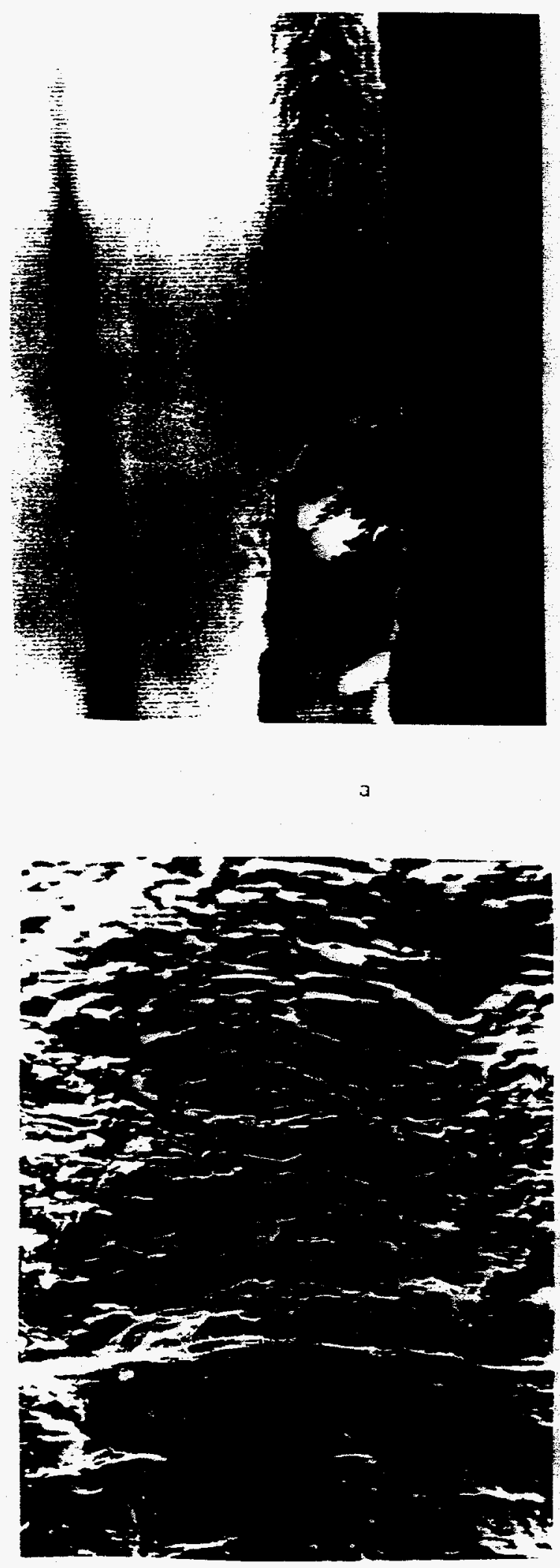
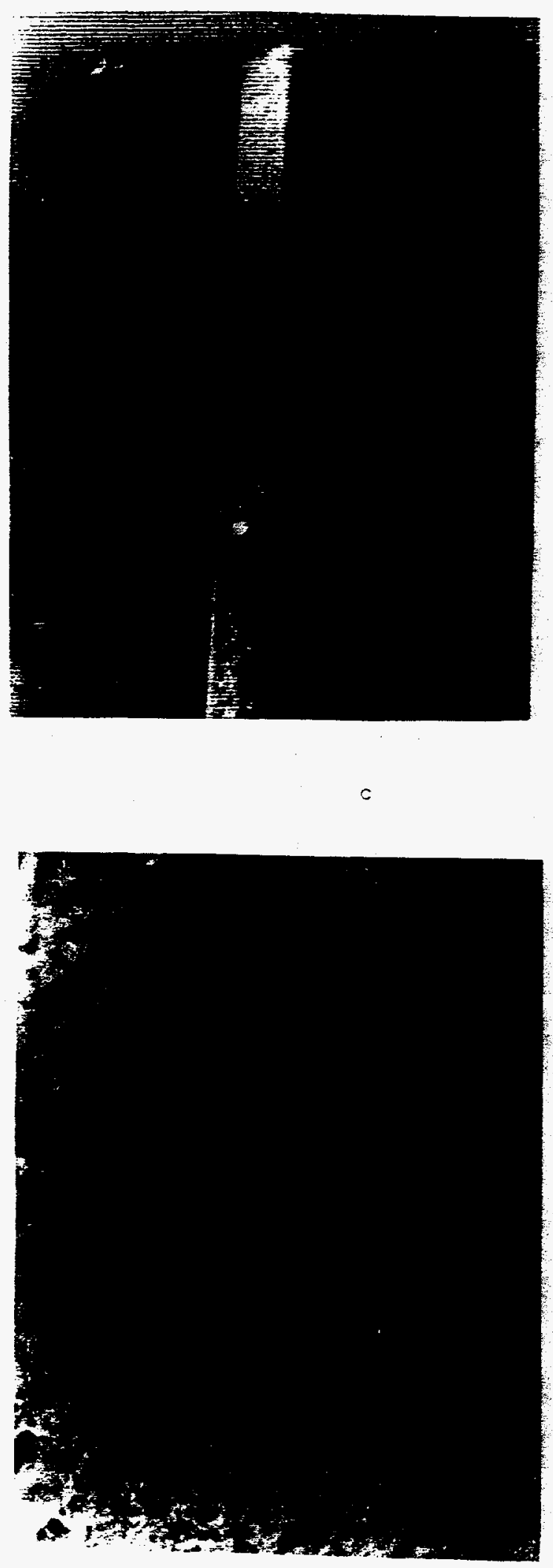

d

Fig. 3 
Fabritsrev etal. Fig. 4

EFECT OF IRAABHATION TEMPERATURE: ON THE UNIEORM ELONGATION-OF CUCTZT

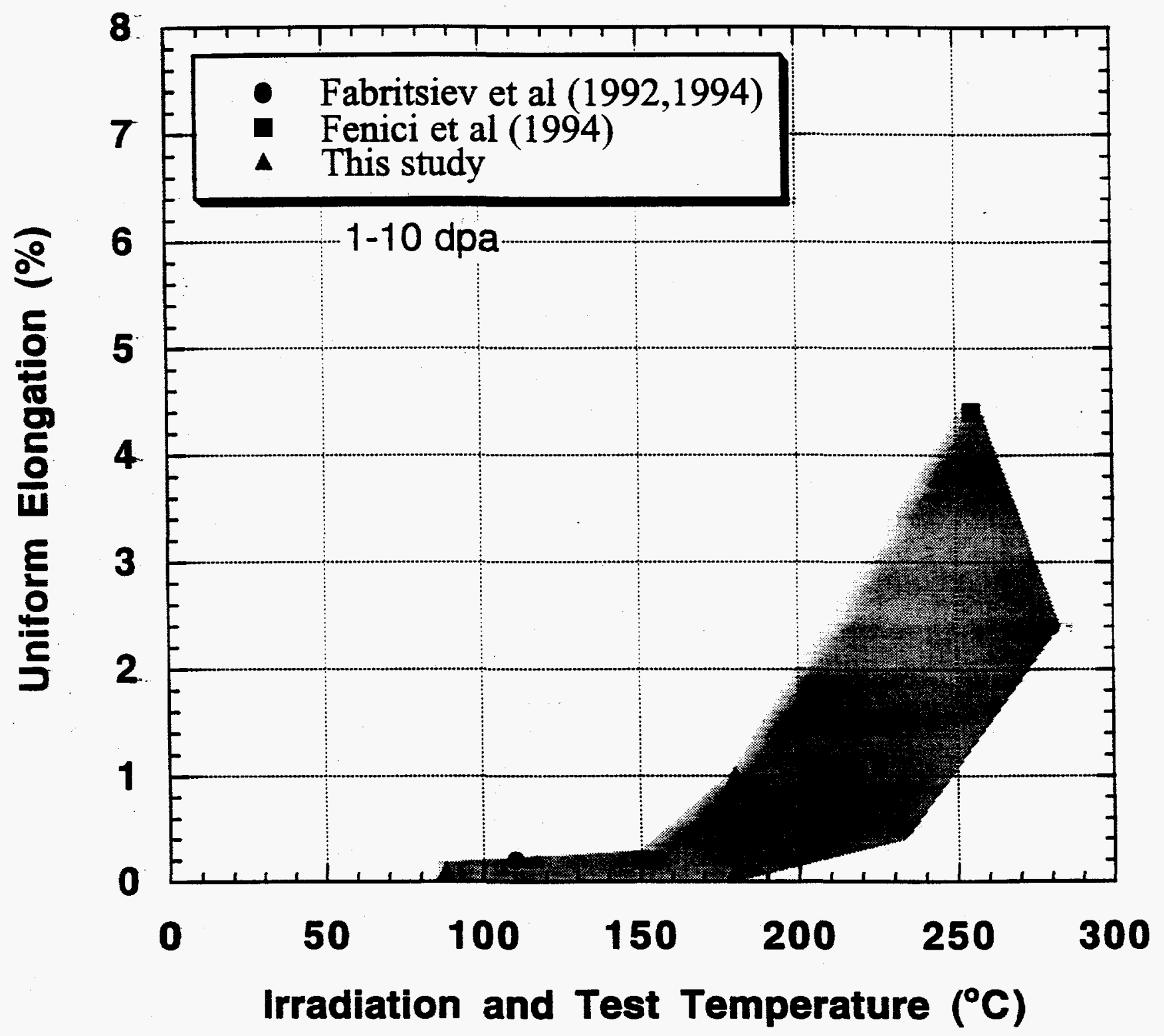


FEMPERATURE-DEPENEENT UAHFORM-ELONGATION IN NEUTRONTRPAQHATED-BISPERSION STRENGTHENEO COPPER

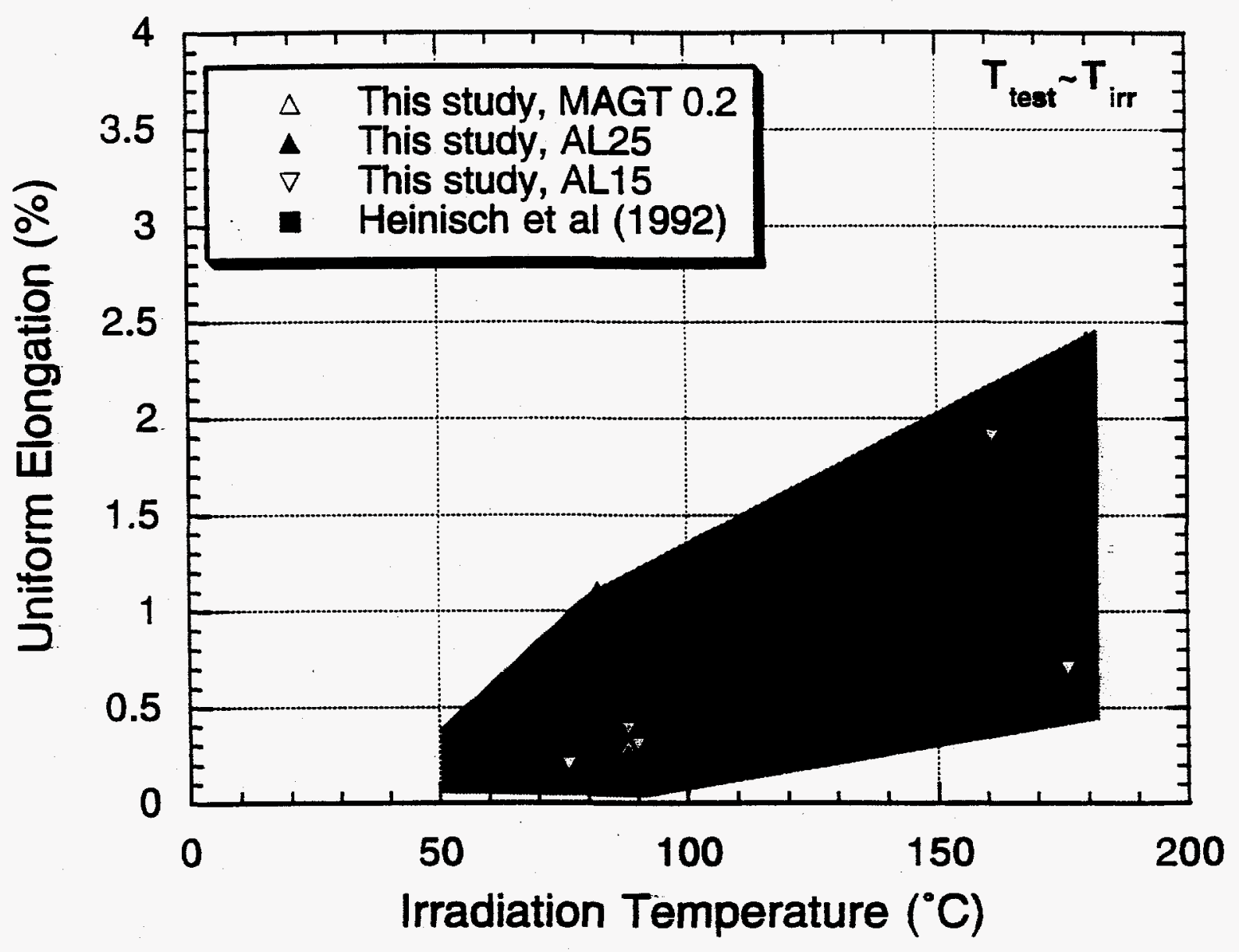




\section{Fabritsrev etal. Fig. $6 a$}

EFFECT OF LOW TEMPERATURE IPAABHATHON ON THE DUCTILITY OF CUCFZY ALLOYS

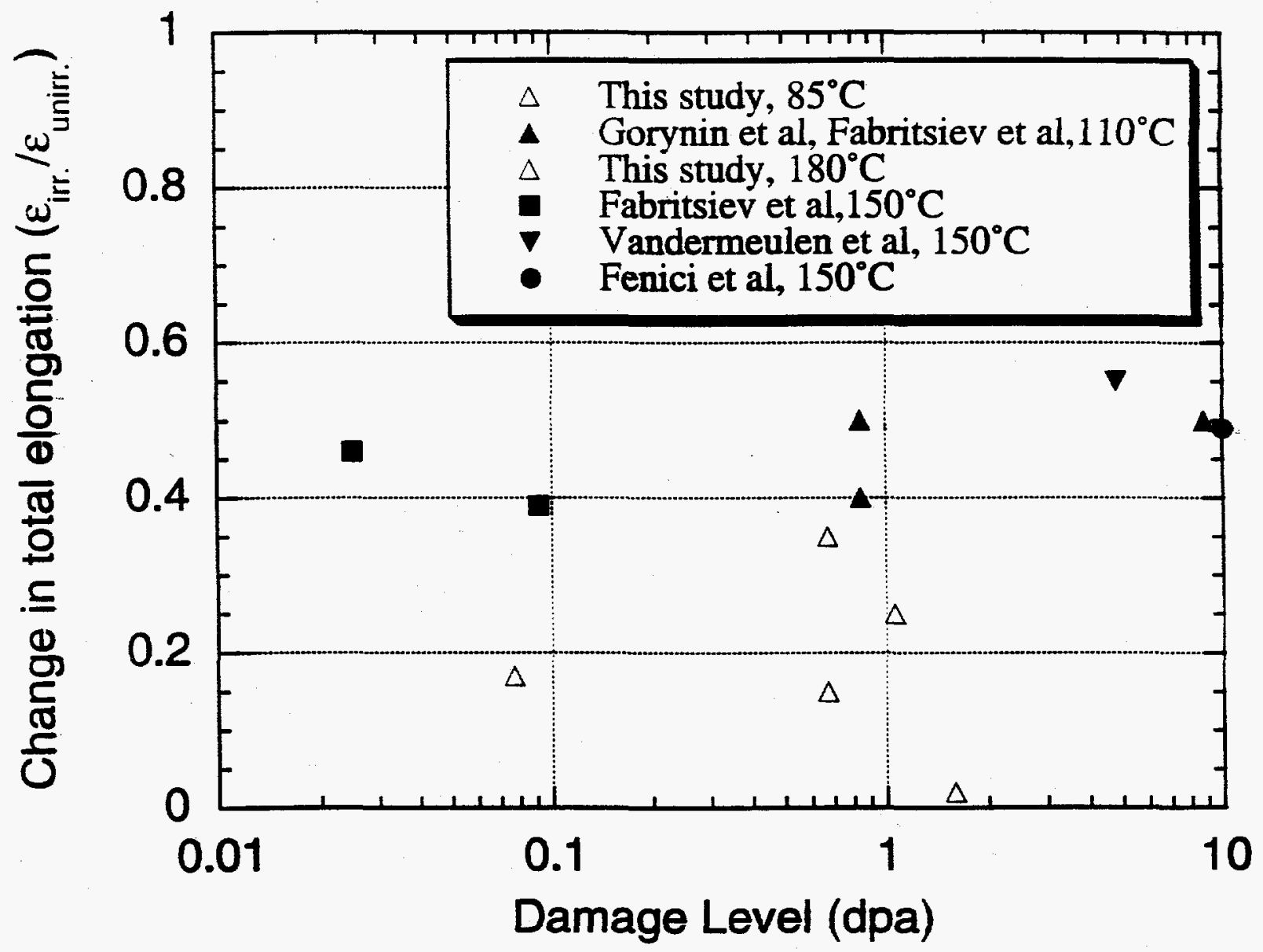


Fabritsievetal. Frg. 66
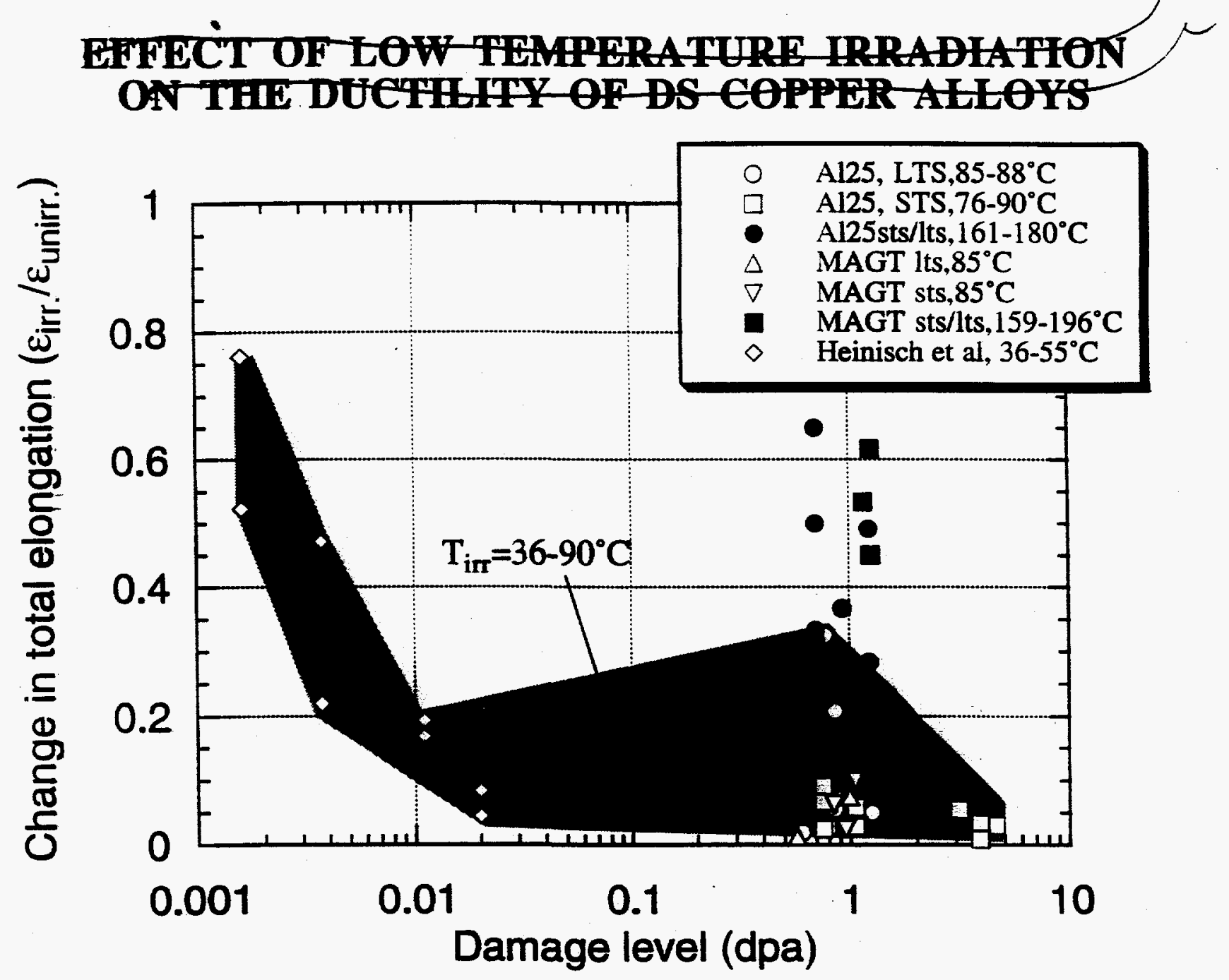

\section{DISCLAIMER}

This report was prepared as an account of work sponsored by an agency of the United States Government. Neither the United States Government nor any agency thereof, nor any of their employees, makes any warranty, express or implied, or assumes any legal liability or responsibility for the accuracy, completeness, or usefulness of any information, apparatus, product, or process disclosed, or represents that its use would not infringe privately owned rights. Reference herein to any specific commercial product, process, or service by trade name, trademark, manufacturer, or otherwise does not necessarily constitute or imply its endorsement, recommendation, or favoring by the United States Government or any agency thereof. The views and opinions of authors expressed herein do not necessarily state or reflect those of the United States Government or any agency thereof. 